\title{
Growth and Characterization of Mixed Urea and Thiourea NLO Organic Crystal
}

\author{
Shobha Kulshrestha ${ }^{1}$, A.K. Shrivastava ${ }^{2}$ \\ ${ }^{1}$ (Department of Physics, Jiwaji University, Gwalior 474011,India) \\ ${ }_{2}^{2}$ (Department of Physics, Jiwaji University, Gwalior 474011,India)
}

Paper id: F45029

\begin{abstract}
The single crystals of Urea-Thiourea, a nonlinear optical organic (NLO) material, were grown by slow solvent evaporation technique at $40-45^{\circ} \mathrm{C}$ temperature. Two solvents viz. Acetone and water were used as solvent. The crystals so obtained were good in size and transparent in visible region of the spectrum. The grown crystals were subjected to different Characterizations such as structural and Optical characterization using $X R D, F T I R$, and UV spectrophotometer. The XRD results show that crystals are perfectly Crystalline in nature and bears orthorhombic structure. The lattice parameters so calculated from XRD are $a=7.62 \AA, b=8.44 \AA$, $c=5.51 \AA$. Fourier transform infrared (FTIR) were recorded to confirm the functional groups. These results indicate that grown crystals have two amide functional group and one carbonyl group. UV visual transmittance studies show that the grown crystals have optical transparency over the entire visible region and the cut-off wavelengths occurs at 201, $252 \mathrm{~nm}$. The optical energy gaps for Urea-Thiourea crystals were found to be $4.2 \mathrm{eV}$ $\& 3.8 \mathrm{eV}$, grown using different solvents.
\end{abstract}

Keywords: Diffraction, evaporation, ftir, nlo, UV study..

\section{Introduction}

Nonlinear optics is given increasing attention due to its wide application in the area of laser technology, optical communication and data storage technology [1-2]. Organic materials are emerging as an alternative to inorganic materials because of their low cost, ease to fabrication. The organic materials posses low dielectric constants, inherent synthetic, high optical damage thresholds comparable to inorganic materials. Urea is one of the simplest an organic compound with the chemical formula $\left(\mathrm{NH}_{2}\right)_{2} \mathrm{CO}$. The molecule has two amide $\left(-\mathrm{NH}_{2}\right)$ groups joined by a carbonyl $(\mathrm{C}=\mathrm{O})$ functional group. It is highly soluble in water and non-toxic. The melting point of urea is $133^{\circ} \mathrm{C}$. Urea crystals attract the attention due to the non-linear optical properties [3].Thiourea is an inorganic compound. It belongs to the orthorhombic crystal system. The growth of urea is problematic owing to its polar electrical properties, which raise the interaction between growth surfaces and molecules of solvent and solute. For that reason they usually show irregular growth habit [4]. Hence in order to get better growth habit we have tried to grow the strongly organic compound of urea and inorganic compound thiourea. In present paper, we report the condition for the growth of good quality single crystals of urea by slow evaporation method using acetone and distilled water as solvents. The grown single crystals were subjected to characterization techniques like X-ray, FTIR, UV-spectroscopy.

\section{Experiment}

\subsection{Synthesis and crystal growth}

The organic compound was synthesized by the combination of urea and thiourea along with acetone and distilled water. Homogeneous solutions were prepared by dissolving $3.4 \mathrm{gm}$ urea and $6.6 \mathrm{gm}$ of thiourea, $1 \mathrm{gm}$ urea and $9 \mathrm{gm}$ thiourea in $25-30 \mathrm{ml}$ acetone, distilled water of each. The two solutions were thoroughly mixed by constant stirring and heated to a temperature of $30-35^{\circ} \mathrm{c}$ for $2-3$ hours. The solutions were then filtered out kept undisturbed. After a period of 1-2 weeks, crystalline material of urea was separated out and dried using a vacuum oven. As show in fig (1), (2).

\subsection{X-ray diffraction analysis}

\section{Result And Discussion}

To obtain the unit cell parameters and to determine the structure of the grown crystals. The study was performed at RR-CAT Indore; copper K $\alpha$ radiation of wavelength $1.540 \AA$ was used in all diffraction studies. The samples were scanned over the range 0 to $60^{\circ}$ at a scan rate of $1 \%$ min. The X-ray diffraction patterns of urea-thiourea crystals are shown in fig $(3,4)$.The peaks were indexed by comparing the XRD data with the standard data given in the literature $[5,6]$. It found that crystals were perfectly crystalline in nature and orthorhombic structure with (110) orientation. For the urea calculated lattice parameter values are $a=7.62 \AA b=$ $8.44 \AA \mathrm{c}=5.51 \AA$. 


\subsection{FTIR Spectroscopy}

Infrared spectroscopy is effectively used to determine the molecular structure and identification of functional groups in the synthesized compound. FTIR spectrum was recorded using spectrophotometer by $\mathrm{kBr}$ pellet technique in the region $4000-500 \mathrm{~cm}^{-1}$. For the organic molecule, the FTIR region has been divided into fractional group and fingerprint region. The fingerprint regions are those lying between 1340 to $900 \mathrm{~cm}^{-1}$, whereas fractional group region extends from 4000 to $1300 \mathrm{~cm}^{-1}$. The FTIR spectrum of urea-thiourea crystal shown in fig $(5,6)$. From the figures at the band $3801,3805 \mathrm{~cm}^{-1}$ clearly indicates $\mathrm{O}-\mathrm{H}$ stretching, presence of hydrogen bonding in the crystal lattice. The band at $3372,3380 \mathrm{~cm}^{-1}$ indicated $\mathrm{NH}_{2}$ asymmetric stretching. Wave number $2687,2688 \mathrm{~cm}^{-1}$ indicated $\mathrm{C}-\mathrm{H}$ stretching and $\mathrm{C}=\mathrm{O}$ stretch of carbonyl group display at 1624 , $1617 \mathrm{~cm}^{-1}$. The strong and sharp band at $1473,1472 \mathrm{~cm}^{-1}$ to indicated $\mathrm{NH}_{2}$ asymmetric deformation. The band appearing at $729 \mathrm{~cm}^{-1}$ infers the $\mathrm{C}-\mathrm{O}-\mathrm{H}$ stretching of the urea-thiourea crystal $[7,8]$.

\subsection{UV- Visible Spectroscopy}

The optical transmittance range and transparency cut-off are important in optical application. The UVVisible spectrum of urea-thiourea was recorded using shimadzu UV- spectrophotometer in the range 200-900 $\mathrm{nm}$ shown in fig $(7,8)$. As shown in fig. the material have a good optical transmittance in the entire visible region. The UV cut-off wavelengths are found to be at 201, $246 \mathrm{~nm}$. The optical band gap are obtained by plotting the graph between $h v$ versus $(\alpha h v)^{2}$ fig $(9,10)$. From the graph, the optical energy band gaps of urea thiourea mixed crystals are $4.2 \mathrm{eV} \& 3.8 \mathrm{eV} .[9,10]$.

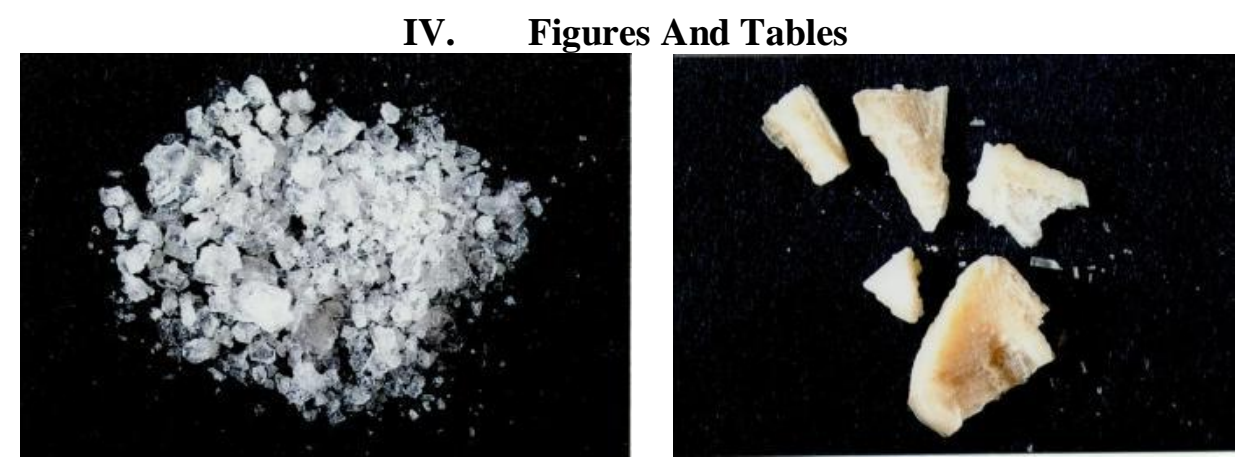

Fig.(1,2): Mixed crystal of urea thiourea with acetone and distilled water.
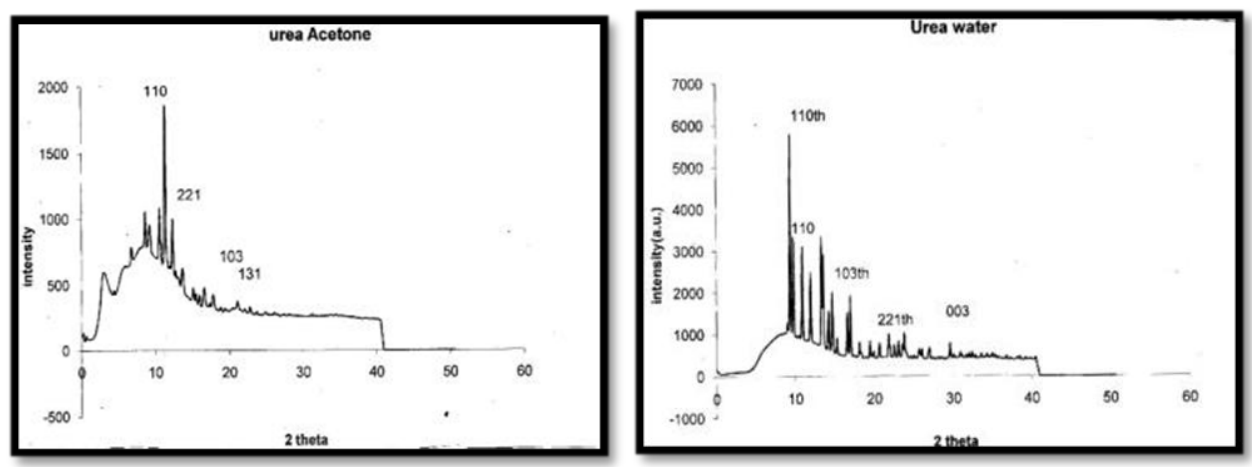

Fig. $(3,4)$ : XRD Spectrum of urea thiourea mixed crystal with acetone and distilled water
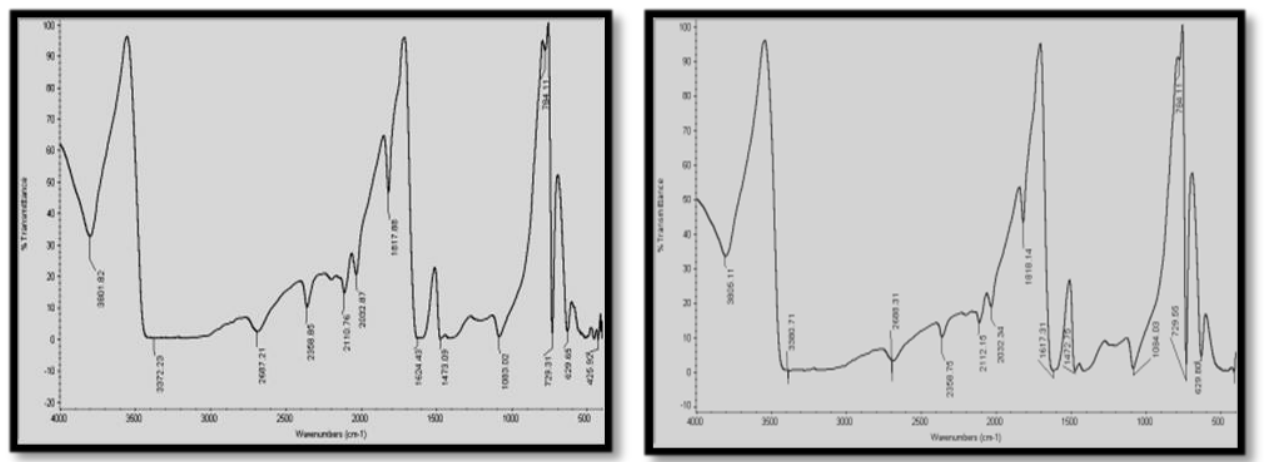

Fig.(5,6): FTIR Spectrum of urea thiourea mixed crystal with acetone and distilled water 

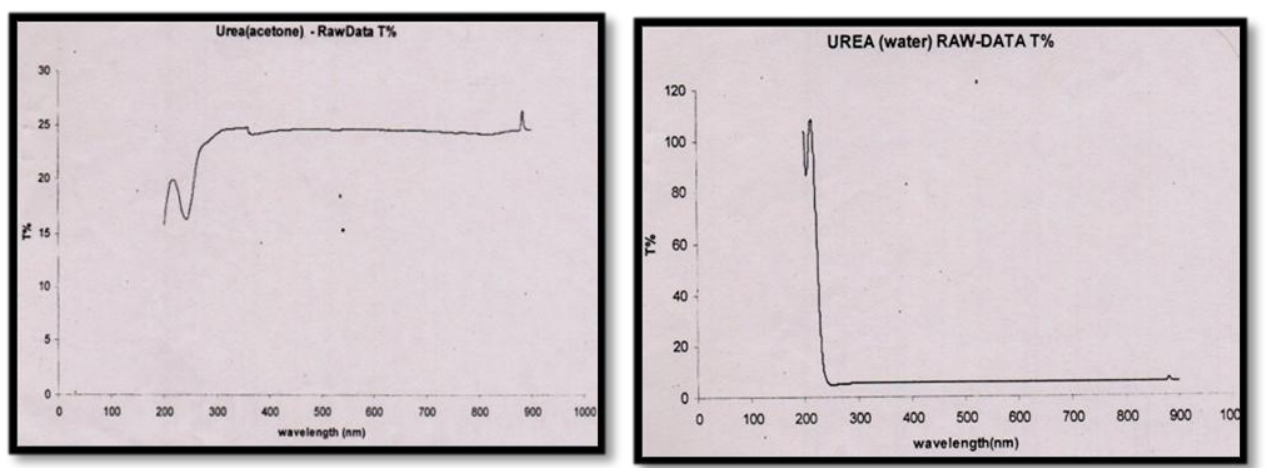

Fig. $(7,8)$ : Transmission spectra of urea thiourea mixed crystal with acetone and distilled water.

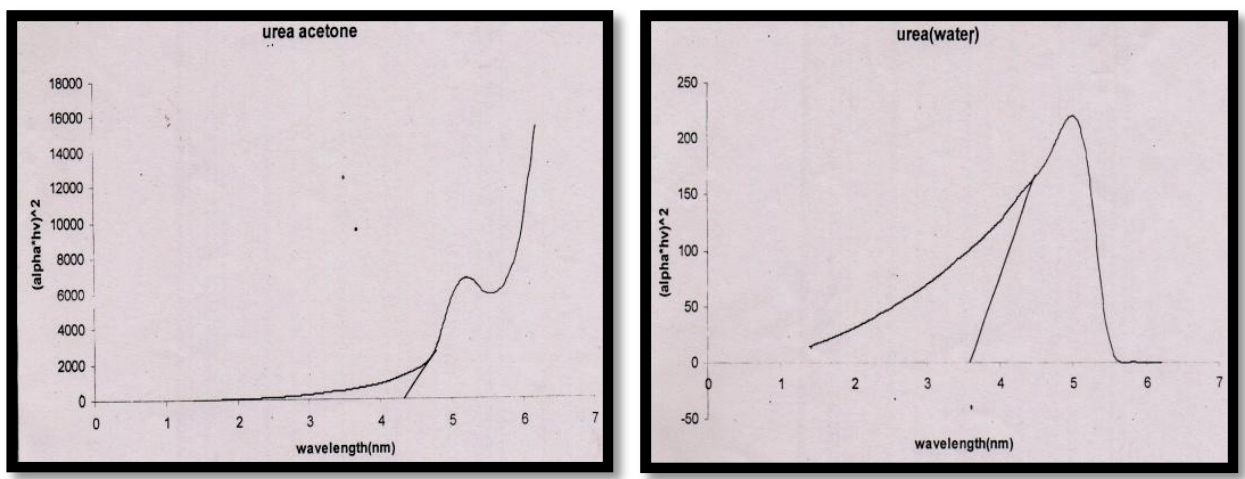

Fig. $(9,10)$ : Energy band of urea thiourea mixed crystal with acetone and distilled water.

Table (1): Lattice parameter of urea thiourea mixed crystal

\begin{tabular}{|c|c|c|c|}
\hline Values reported in literature (in $\AA$ ) & $\mathrm{a}=7.6212$ & $\mathrm{~b}=8.5427$ & $\mathrm{c}=5.5019$ \\
\hline Experimental values (in $\AA$ ) & $\mathrm{a}=7.62$ & $\mathrm{~b}=8.44$ & $\mathrm{c}=5.51$ \\
\hline
\end{tabular}

Table(2): Wave number assinment for urea thioure mixed crystal

\begin{tabular}{|c|c|}
\hline Wave number cm & -1 \\
\hline 3801,3805 & $\mathrm{OH}$ stretching of water \\
\hline 3372,3380 & $\mathrm{NH}_{3}{ }^{+}$asym. Stretching \\
\hline 2687,2688 & $\mathrm{C}-\mathrm{H}$ stretching band \\
\hline 1624,1617, & $\mathrm{C}=\mathrm{O}$ stretch of carbonyl group \\
\hline 1473,1472 & $\mathrm{NH}_{3}{ }^{+}$asym.deformation \\
\hline 784,784 & N-H-N stretching \\
\hline 729,729 & C-O-H stretching \\
\hline
\end{tabular}

\section{Conclusion}

The single crystal of organic compound urea thiourea was grown by solvent evaporation technique at $40-45^{\circ} \mathrm{c}$ temperature using different solvents like acetone \& distilled water. It is clear that crystals are pure transparent of different length and width. The excellent transparency in the entire UV-visible region, thus confirming the suitability of this material for second harmonic generation applications. The energy band gaps are observed $4.2 \& 3.8 \mathrm{eV}$. FTIR spectrum reveals that the functional groups of the grown crystal. Single crystal $\mathrm{X}$-ray diffraction technique was used to estimate the cell parameters and the compound easily crystallizes in an orthorhombic structure with (110) plane. The peaks indicated that crystal is perfectly crystalline in nature.

\section{Acknowledgement}

The authors acknowledge Dr. A.K. Shrivastava (school of studies Jiwaji University Gwalior) for useful discussion and constant encouragement. 


\section{References}

[1] Santhanaraghavan, P., Ramasamy, P. (2001). Crystal growth process and method. India, KRU publications.

[2] Achintya, K. Bhowmik, Shida Tan, Ayayi C. Ahyi, J.A. Dharmadhikari,K. Dharmadhikari and D. Mathur, Optic commun. 280, 472 (2007).

[3] G. Ramesh Kumar, S. Gokul Raj, R. Sankar, R. Pandi and R. Jayavel, J. Cryst. Growth. 267,213 (2004).

[4] Madhavan J, Arun S, Thomas P C, Vimalan M, Rajasekar S A, and Sagayaraj P, Cryst. Res. Tech, 2007;42;59-64.

[5] Kal Qui J and lan, mater sci B , 133(2006) 191.

[6] Shah c ,J phys condence matter, 15 (2005) L (669).

[7] Saima J Grukova A and papanova M, J Elect Eng, 56 (2005).

[8] Bhat S G \& Dharmaprakash S M, J Cryst Growth, 181 (1997) 390

[9] N. Vijayan, R. Ramesh babu, R. Gobalakrishnan, S. Dhanuskodi and P. Ramasamy, J. Cryst. Growth., 236 ,407 (2002).

[10] S.K. Kurtz, T.T. Perry, J. Appl. Phys., 39, 3798 (1968). 